THE PARK AVENOE TUNNEL CAVE-IN.

The preliminary borings which were made along the route of the entire subway during the survey befor construction, showed that the tunnel between 34 th and $42 \mathrm{~d}$ Streets would be built through a bed of solid rock. The tunnel has been driven through, both on the east and west side of Park Avenue, for this entire distance of 1,800 feet. In some sections, indeed throughout the greater part of it, the blasting has been done to the full section required. The tunnel as thus roughly blasted out is 30 feet in width 12 feet in height to the springing of the elliptically-arched roof, and 6 feet from the level of the top of walls to the crown of the roof, making a total height inside of 18 feet. Generally speaking, the tunnel was driven in two headings, the lower heading rectangular in cross section, 12 feet in height by 30 feet in width and the upper heading 6 feet in height to the crown of the elliptically-curved roof. After the tunnel is blasted out to the dimension given above, the floor, sides, and roof are lined with a heavy wall of concrete, and the space between the wall and the irregular surface of the rock, as left by the blasting, is filled in rendering any caving in of the rock impossible.

Commencing at 34 th Street, on the east side, the first 200 feet of the tunnel has been entirely excavated with the exception of the roof from which about 4 feet have yet to be blasted off. The next 500 feet have been taken out en tirely, the concrete side walls are in place, and for about 80 feet of this distance the roof has been turned in. For the next 300 or 400 feet, from about 37th Street to the middle of the block between 38th and 39th Streets, the bottom heading has been taken out, and in the upper heading a maximum depth of 6 feet has yet to be blasted down. It is in this stretch of work that the slide occurred. In the next 200 feet the upper heading, for a depth of 12 feet from the roof down has been taken out, and about 6 feet remain to be blasted away to bring the tunnel down to the grade. The remaining 500 feet to $42 \mathrm{~d}$ Street has been entirely blasted out, ready for concreting.

The accompanying illustrations include a profile and cross-section and a plan view of the easterly tunnel, at the point where the cave-in occurred, and show very clearly the causes and nature of the trouble and the means taken to remedy it. The bottom of the tunnel is 60 feet below the street surface. The heading at this point is 12 feet in height by 30 feet in width. The distance from the roof of the

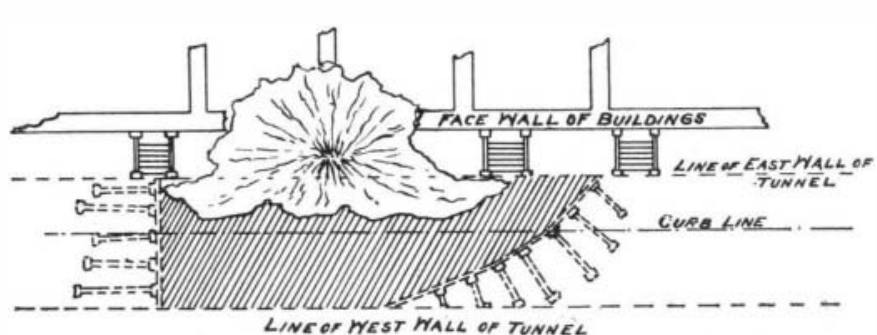

PLAN VIEW OF CAVE-IN, SHOWING CRATER AND BULKHEADS.

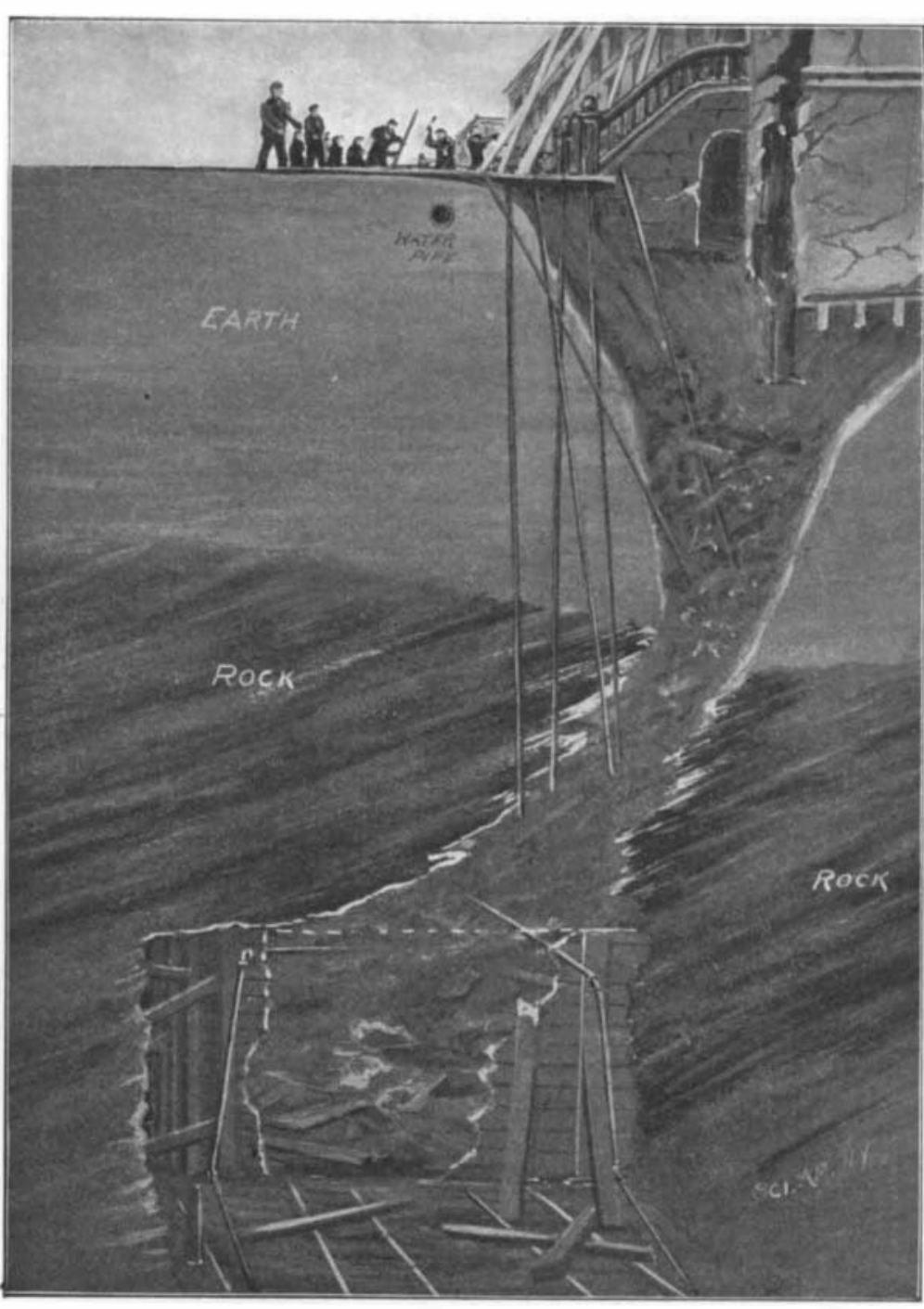

CAVE-IN, SHOWING THE METHOD OF REPAIRS BY BULKHEADING AND GROUTING.

4-foot layer of rock and allowing it to slide bodily into the tunnel. In spite of the endeavors made to into the tunis. In spite of the endeavors made to crushed in and a section of the roof 70 feet in length by sev- toward the surface. On either side of the rock was a thin layer of greasy decomposed material, somewhat the nature of soapstone, and the heavy rains and thaws of the winter, aided by a broken water pipe,

the

1We opening of the kind shown in our illustrations. Unfortunately, the foundations of the front wall of the adjoining houses on Park Avenue were resting upon this loose material-a perfectly secure foundation so long as the rock beneath was undisturbed, but, as the event proved, a very unstable one when the event proved, a very unstable one when the the foundations of this wall, with the conse quence that the areas, front steps, foundation walls and a portion of the brownstone fron of the houses affected fell.

It was first proposed to make an open cut at this point, build a concrete lining for the tunnel, and subsequently filling in above it; but it has now been decided to carry out the repairs in the manner indicated in our sketch, employing a system of grouting which had been used on a previous occasion by Mr. Shaler, the contractor, during repair work in the construction of the new Croton Aqueduct. It is well known to engineers that a mass of loose material (broken rock, gravel, etc.) may be formed into one solid monolith by introducing pipes into it and forcing through them fine "grout," a liquid cement of the proportions of one of sand and one of cement. Driven in under pressure the grout flows throughout the whole mass, filling the interstices, and, in its subsequent solidification, bonding it in one solid monolith.

In applying the principle in the present case, strong bulkheads of timber were buil across the tunnel at either end of the slide, and a mass of broken rock and stone was dumped into the crater above; about a dozen pipes were then carried into the interior of the mass, six of them from the surface above and three from the bulkheads at either end, and the grouting driven through them into the material by means of force pumps. No effort is being made to solidify the whole mass of debris in the tunnel, but merely that which lies around the roof in the neighborhood of the break. Similarly, only the material in the lower half of the crater will be thus grouted. When the mass has set, it will be perfectly safe to excavate the tunnel to its full width. The new foundations for the front of the houses that have been injured will be then carried right down to the underlying rock, and, as thus restored, they

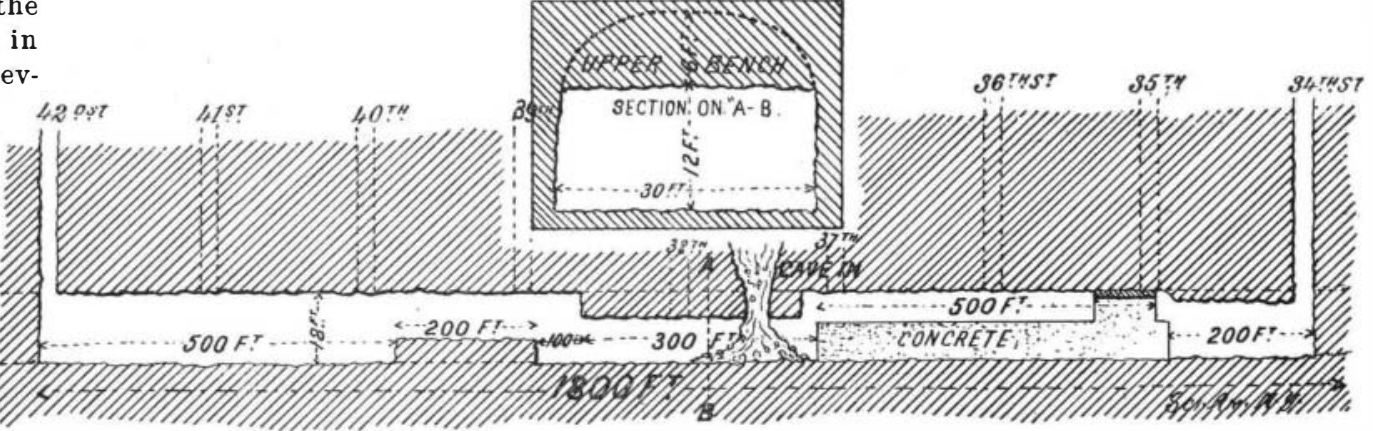

PROFILE OF THE EASTERLY TUNNEL, SHOWING PRESENT STATE OF THE WORK. heading to the street level is, therefore, 48 feet. In general, the solid rock in which the tunnel lies extends nearly to the surface, of Park Avenue; but be tween 37th and 38th Streets there is a depression or basin in the rock, and its surface lies, as indicated in our drawing about 28 feet below the surface of the stret, or about 20 feet above the roof of the tun heading. Above the rock heading. Above the rock
lies a mass of what tha lies a mass of what the engineers call earth, that
is to say, a loose material is to say, a loose material clay, etc., of a consistency which can be easily excavated by pick and shovel, and which has no natural cohesion to hold it in place.

On the Wednesday preceding the day on which the trouble occurred, it was noticed that there were indications of settlement of the rock, and a section of rock measuring about $3 \times 6$ feet fell through into the tunnel. An examination of the cavity revealed a stratum of decomposed rock, about 4 feet in thickness, which extended diagonally at an angle of about 45 degs. eral feet in width slid into the tunnel. Now, the effect of this section of rock falling in, was roughly speaking, as though the valve at the bottom of a hopper had been opened, allowing the loose contents above to flow down through the opening thus formed. The loose gravel, sand, earth, etc. poured into the tunnel, forming above the rock layer a crater-

\section{THE NEW BERMUDA FLOATING DOCK}

The new floating dock recently launched on the Tyne, England, from the works of Messrs. C. S. Swan \& Hunter, for the use of the British fleet at Bermuda, claims the distinction of being the longest and heaviest dock so far constructed. It has a length over all of 545 feet, while the hull weight of the structure, by which is meant the quantity of steel plates, Dars and shapes, rivets, bolts, etc. and all other material essentially necessary to a dock, but not including machinery, timber or any other fittings, is just over 6,500 tons. The great Algiers dock dt New Orleans certainly runs it very close, having a length of 525 feet and a hull weight of 5,850 tons.

The dock is to replace the famous old structure at Bermuda which was towed across the Atlantic in 1869, and has now become obsolete, not through age, but through the insufficiency of its di. mensions. The length of the old dock was 381 feet 
over all, but to obtain its maximum lifting power gates were fitted, which reduced its practical length to 330 feet. Its inside width was 84 feet between side walls, and its lifting power was 8,000 tons, which was sufficient for the ships of the "Bellerophon" class, to lift which it was specially designed, although it wa capable of bringing the keel out of the water of vessels up to 10,200 tons, the then heaviest ships of the day iepresented by the long fully-rigged line-of-battle ship "Agincourt" and "Minotaur." The present dock is 545 feet long, and having no gates, the length of ship it can take is not restricted; its clear width of en trance between rubbing fenders is 100 feet. Its lifting power up to the pontoon deck level is 15,500 tons, but by utilizing the shallow pound this can be increase to 17,500 tons, and the walls are of a sufficient height to allow of a vessel drawing 32 feet to be taken on 3 feet 6 inches keel blocks.

The present dock is of the type known as the float ing graving dock, the invention of Messrs. Clark Standfield, of Victoria Street, Westminster, London, from whose plans it was built, and who also designed the famous Algiers dock and many other similar structures. It was this firm who designed the Havana dock, which was built and launched by the same firm, Swan $\&$ Hunter, in the record time of seven and a half months. Before describing the present structure it is interesting to note the work to be done by the new dock, which is of a somewhat varied nature.

In the first place, it is primarily intended to lift battleships of the largest class, displacing about 15,000 tons on a 27 feet 6 inches draught, and of a length of 390 feet, but with a bearing length of keel of only 343 feet. It has, however, also to deal with lon cruisers of the "Terrible" class, of a displacement of 14,200 tons on a 27 -foot draught, a length of 500 feet between perpendiculars and a bearing keel of 383 feet; and lastly, it may be called upon to lift the auxiliary steamships of the subsidized mail lines, of which the "Campania" may be taken as a type. This ship in full fighting trim may displace as much as 19,000 ton on a 31-foot draught, but in ordinary docking condition, without full coal supply aboard, her weight wi be about 16,500 to 17,000 tons. The length of this type of vessel is 600 feet between perpendiculars, while the bearing length of keel is 502 feet 8 inches. dock:

Length over all. ...

Breadth over all.

Length of end pontoons.

Length of middle pontoon.

Breadth between walls.

Width of pontoons.

Height of vertical walls.

Length of vertical walls.

Thickness of walls.

Lifting power up to deck

$$
\begin{array}{r}
\text { level } \ldots \ldots \ldots \ldots \ldots \\
\text { Extreme lifting power... } \\
\text { Total weight of hull..... }
\end{array}
$$

The dock itself consists of five portions, comprising

three pontoons, which form the main lifting portion of the dock, an' two side walls, which, while affording a tertain amount of lifting capacity, primarily serve to give the structure stability and to regulate its descent when the pontoons are submerged. The pontoons them. selves are of different sizes and form; the center one, which is 300 feet long, is rectangular in shape, but the two terminal ones, which are 120 feet in length, have each 71 feet of their length rectangular, the remainder being finished off in the form of a blunt-nosed point or bow. The sides of the rectangular portion of all the pontoons are built up so as to form a broad altar, standing 12 feet above the dock. The side walls, which are of the same length as the rectangular portion of the pontoons, come along each side of these and are attached there by means of strong steel castings, riveted to their respective outside skins, and connected together by double fishplates and tapered pins.

The pontoons of the dock are further divided into forty pumping divisions, of which thirty-two are absolutely watertight and distinct. The side walls have each eight watertight divisions. All these fifty-six divisions are provided with a separate pipe, each governed by a separate valve. The pipes in the starboard half of the dock are led directly into the main drain in the starboard wall, and all those in the port half to a similar drain in the port wall. These drains are continuous over the whole length of the walls, and the four 16-inch centrifugal pumps in each wall are seated directly on them, so that any one pump can empty an the compartments of its half of dock.

Although the dock is divided into flfty-six divisions, each with its own regulating valve, the working of the whole dock is all done from two central positions on the top of the towers. Here are grouped in the valve houses ordinary signal levers, which by means of rods and cranks connect to the different valves. Each valve house is in direet communication by speaking tubes with its engine rooms, so that the man in charge can manipulate every valve, both water and steam, re çuired for the maneuver of the dock without quitting his station. Each valve is further fltted with an indicator, which shows on top of the valve house exactly which valves are open and which shut, so that the dockmaster can see from any conning position he may take exactly how his craft is being regulated on both sides. It is interesting here to note the difference between the English and American methods of berthing a ship on a floating structure. The English custom, and also that of Italy and Japan, is to support the armor belt on more or less vertical shores inserted under an angle iron firmly attached to the same. These shores are put in position as the ship is rising, and, as the wate recedes, more and more shores are inserted. In the case of the dock under notice, large and heavy altar have been constructed for this purpose. The American method, on the other hand, is to strengthen the bilges of the ironclads with strong bilge docking keels, form ing, with the keel proper, a level bottom. No shores, therefore, are required beyond those absolutely necessary to roughly center the vessel, and no great care is required in adjusting the berth, and one set of bilge blocks does for all sizes of vessels. Mr. Lyonel Clark, of Messrs. Clark \& Standfield, did not hesitate to express to the writer his preference for the American system. It affords a great saving in weight and quantity of shores, and what is more important a great saving of time, for in the American plan it would be perfectly feasible to dock a vessel completely in the time required to center and adjust her with shores disposed according to English practice.

Although somewhat larger in its outside dimensions, the dock has by no means the lifting power of the Algiers structure. This latter will raise a weight of 18,000 tons up to pontoon level, which could even be increased to 20,000 tons by utilizing the pound, making it the most powerful dock in the world. As already stated, the extreme lifting capacity of the Bermuda dock is 17,500 tons

This latest equipment to the British navy was successfully launched on the Tyne on Saturday, February at the time. At the appointed moment the buge craft glided into the water, and was brought to rest within a distance of about 25 feet. It is expected to be completed about the end of April, when it will be brough to Chatham, on the Medway, where it will be thoroughly tested by docking a battleship, after which it will be towed to Bermuda.

London, England.

THE GLASS PALACE IN "BEAUTY AND THE BEAST." In the modern spectacular play it is often necesin producing startling scenic effects. We illustrate (on our front page) the Crystal Palace and Illuminated Fountain, which is introduced in the Drury Lane production called the "Beauty and the Beast." Most of the duction called the "Beauty and the Beast." Most of the
pantomimes and other attractions of like nature originate in London, the people of that metropolis bein very fond of such displays. "Beauty and the Beast," which is now running at the Broadway Theater, New York, taxes the resources of the theatrical engineer to the utmost. The story of the play is one which doe not call for special comment. It deals with the wellknown episodes in the fairy tale, in which the daughter of a princess receives gifts from her fairy godmother but the hapless child receives also the curse of a malignant witch. The thread of the story runs through the performance, which consists largely of splendid processions and ballets, including an aerial ballet which is a most beautiful and ingenious affair. In the last scene the curtain rises on a glass palace, shown in th front page engraving. In the palace proper and on the steps are grouped the ballet and chorus, and in front is an illuminated fountain. The palace was made in Vienna for the Drury Lane Theater, and is compose of 33,000 pieces of glass. The structure was dismantled and shipped to this country, and was re-erected by Messrs. Klaw \& Erlanger for the Broadway The ater. It is lighted by 2,000 incandescent lights of small candle power, two and four, and an immense arc light in the roof. The numerous difficulties connected with the storing of the glass palace when not in use were obviated by simple but ingenious means. An immense pit was blasted out of the rock below the level of the stage cellar, to a depth of 20 feet. Heavy beams wer placed at the bottom to bear the weight, and heavy tim bers were put in to support the stage proper and it load. Normally, the glass palace rests in this pit, the top projecting almost to the level of the stage, the glas crown which surmounts it being removed. Some te minutes before the curtain is raised, preparations are begun for raising it. The platform carrying the palace is counterweighted by eight tons of iron. 'It is raised with the aid of two winches and a bull or purchase wheel, and some seven men are required to raise the platform. The first step is to remove the stage floor, which is run into the flies and hooked up against the rear wall of the theater. Ropes are now let down from the gridiron at the top of the stage by men who operate the bull-wheels. The trussed beams which support the stage are then raised out of view. Signals are

given by means of cords which pass through the stage floor. The palace is raised in a few minutes with great ease. The platform on which it rests reaches the stage level, and is brought to exact position by means of screw jacks at the four corners. The palace rests upon rollers. Two winches, shown at the rear, serve to draw the palace back some 15 feet. This is necessary, owing to the fact that the foundation for the rear wall was not of the best, due to veins of water, and it was, therefore, deemed well to sink the pit as far forwar as possible. The same winches are used to draw the palace back onto its platform when it is to be lowere Connection is made with the large switchboard, shown at the rear; the palace also carries its own switchboard. The electric lighting is most interesting. There are 2,000 feet of cable used, and the lighting is accomplished by the Elbright system, which consists of two cables with a wire core capable of being punctured. Each lamp has two pins, one of which passes into each of the two cables. The position of the lamp can be changed at will, it being only necessary to stick in the pins elsewhere and tie with tape. Every part of the palace is brilliantly illuminated, and the effect is one of surpassing beauty.

In addition to the palace proper, there is an illuminated fountain which is also most ingenious. The fountain is carried upon the floor of the palace until the stage level is reached. It is then carried down and placed in front of the balustrade. The various jets are then straightened and tested. Water is admitted from the street, and is divided into seven streams, which in turn furnish seven different rows of jets. Valve wheels with long stems are run through the floor, connecting with valves which control the flow of water to the movable hose. The fountain is illuminated from above, where arc lights are secured to a light-batten, the various colors being produced by rotating disks. By a clever manipulation of the various water jets and movements of the disks, remarkable and beautiful effects are produced.

The flying ballet, which is also a wonderful feature of this play, is the invention of Herr Zschregner, director of the Apollo Theater, Berlin, Germany, and for eight years it has been a standard attraction of the Drury Lane Christmas pantomime. The members of the ballet are all German girls, with the exception of the premiire, who is an English girl. They are all of small, slight figure, and dress in pink-silk tights with black-feather bodices and fronts of white chiffon. They have wings attached, and with their head-dresses they give an idea of something half-human, half bird. Each carries a fluffy, white muff. The costume conceals a corset of leather and iron which incases the en tire trunk of the body. At the top of the back is a brass spring bolt adapted to receive a hook secured to a small wire, which passes up to a machine on the gridiron. They are raised and put through various evolutions by means of the manipulation of ropes by men in the wings. From one to three men are required to manipulate the wire for each dancer. At a signal from the director of the troop, the premirre takes the center of the stage, and is followed by the remainder to marking the place where they are to stand before they are raised, as otherwise a dancer might easily come down upon some of the ballet or chorus. Great care is used in inspecting the apparatus, as the life of everyone of the flying ballet depends upon a wire no larger than a piano wire. The mechanism used in this ballet is carefully guarded, so that no one may see its working. The chief difficulty in this ballet seems to be in finding the true center of gravity of the body. Unlike other ballet dancers, they are hired by the year and not by the engagement or season, as is customary in the theatrical profession. We are indebted to $\mathrm{Mr}$. Claude L. Hagen and to Mr. Bissing of the theater for many courtesies in the preparation of the present article.

\section{The Current Supplement.}

The front page of the current Surplement, No. 1370 presents three handsome illustrations of part of the famous Imperial silver service which the Kaiser placed at Prince Henry's disposal for the banquets given on the "Hohenzollern." Prof. Ramsay discourses interestingly on the "Inert Constituents of the Atmosphere." A new use for blast-furnace slag is described in an article on the Berry hydraulic flag-press. The latest of the big locomotives is shown in an admirable illustration. The first part of an interesting treatise by 